\title{
PROFESSOR MEDIADOR ESCOLAR E COMUNITÁRIO: ASPECTOS POSITIVOS E NEGATIVOS - PERSPECTIVAS A PARTIR DE INTERVENÇÕES E APLICAÇÃO DA JUSTIÇA RESTAURATIVA
}

Juliana Minacca Ulian, Marcos Lupércio Ramos

Universidade do Oeste Paulista - UNOESTE, Curso de Pedagogia, Presidente Prudente, SP. E-mail: julianaangoleira@gmail.com

\section{RESUMO}

A presente pesquisa objetivou analisar o papel do(a) Professor(a) Mediador(a) Escolar e Comunitário (PMEC) e suas contribuições para a melhoria do processo de ensino e aprendizagem no ambiente escolar da educação formal a partir da importância do (a) mesmo (a) para a minimização e/ou soluções de conflitos diversos que ali podem ocorrer. O (a) PMEC tem a possibilidade de construção de elos de conjunção dos esforços da escola e da família em prol da qualidade do processo formativo da criança. Possui cunho qualitativo, consolidando-se pela revisão bibliográfica, entrevistas e estudo de caso com três grupos (famílias, alunos e profissionais da educação), com 70 pessoas. É ressaltada a importância do(a) PMEC e destacada a união famíliaescola como fundamental para desempenho da criança em sua vida escolar, com melhoria do processo de ensino e aprendizagem, objetivando a formação em termos de aquisição de conhecimentos que possibilitem competências e habilidades para o exercício de cidadania.

Palavras-chave: Família; Escola; Parceria; Professor Mediador Escolar e Comunitário.

\begin{abstract}
The present study aimed to analyze the role of the School and Community Mediator (PMEC) and its contributions to the improvement of the teaching and learning process in the school environment of formal education, based on the importance of (a) ) Even (a) for the minimization and / or solutions of various conflicts that may occur there. The PMEC has the possibility of building links of the efforts of the school and the family in favor of the quality of the formative process of the child. It has a qualitative character, being consolidated by the bibliographical review, interviews and case study with three groups (families, students and professionals of the education), with 70 people. It is emphasized the importance of the PMEC and highlighted the family-school union as fundamental for the performance of the child in his school life, with improvement of the teaching and learning process, aiming at training in terms of acquisition of knowledge that provide skills and abilities For the exercise of citizenship.
\end{abstract}

Keywords: Family; School; Partnership; School and Community Mediator. 


\section{INTRODUÇÃO}

O presente trabalho teve como finalidade conceituar e elencar as funções do trabalho do Professor (a) Mediador (a) Escolar e Comunitário (PMEC) na Instituição Escolar procurando destacar e analisar como se desenvolve a função e intervenções diante de conflitos de natureza específicas: Bullying, Agressão Física e Verbal e Indisciplina no ambiente escolar.

Este trabalho é de suma importância, pois, vem a colaborar com os educadores em seus relacionamentos pessoais com os discentes. Os docentes tendem a ter dificuldades em estabelecer o diálogo com os alunos e proporcionar estímulos expressivos para que os mesmos adquiram competências e habilidades em determinadas áreas da educação neste devido momento que a função do mediador (a) estreita a ponte entre educador e educando seja ele fragilizado ou castigado pelas peripécias da vida ou não.

A pesquisa procurou envolver os diferentes tipos de violência na comunidade escolar de uma Escola Estadual da cidade do Estado de São Paulo, a qual apresentava - segundo dados preliminares - um número muito significativo de ocorrências que dificultavam e/ou inviabilizavam o sucesso do processo de ensino/aprendizagem.

O baixo rendimento escolar, a dificuldade no processo de ensino aprendizagem, interação e socialização entre a comunidade, números de conflitos e suas diversas naturezas despertaram o interesse em se fazer um levantamento onde à função do/a Professor (a) Mediador (a) Escolar e Comunitário tivesse acesso aos dados de violência, indisciplina e agressões na Escola.

Diante da carência de estudos na área em relação a pesquisa que foi desenvolvida enquanto relevância acadêmica e social - o intuito foi de refletir, analisar e demonstrar o quanto é necessária a função desempenhada pelo mediador (a) na Unidade Escolar, pois, o (a) mesmo (a) é o (a) facilitador (a) de uma interlocução entre gestão, discentes, docentes e pais e/ou responsáveis. Podendo assim, contribuir para a ampliação do conhecimento sobre essa temática e contínua reflexão da mesma.

Diante dessas premissas iniciais, foram elaboradas algumas hipóteses para análises, dentre os quais de que há na unidade escolar, múltiplos tipos de violências e que as mesmas podem estar interferindo de maneira negativa no processo de ensino e de aprendizagem. Diante disso inicialmente as intervenções e/ou ações da (o) PMEC seriam suficientes para minimizar os índices de violência na escola com a colaboração conjunta da equipe gestora, das famílias dos alunos e dos próprios educandos? Com essa preocupação, buscou-se obter dados que permitissem destacar as ações que mais se mostraram eficientes, assim como das melhores estratégias que pudessem proporcionar bom funcionamento da escola em termos da promoção de sua função básica que é a implementação de métodos de ensino e de aprendizagem e promoção da sociabilidade entre o grupo escolar.

Em termos de objetivo geral, buscou-se analisar e destacar a função do (a) Professor (a) Mediador (a) Escolar e Comunitário (PMEC) na Unidade Escolar e a importância do (a) mesmo (a) para a minimização e/ou soluções de conflitos diversos que ocorrem no ambiente escolar. Paralelamente, destacar os mecanismos que permitem a compreensão do papel e/ou papéis do (a) PMEC para a melhoria da qualidade do ensino. Assim como efetuar levantamento de dados de ocorrências que envolvem formas de conflitos entre alunos e alunos e profissionais da educação como Bullying, Agressão Física e Verbal e Indisciplina. Analisar os dados coletados a partir do viés de suas possíveis influências ao processo de ensino e de aprendizagem. Destacar as ações do (a) PMEC e suas intervenções no sentido da aplicabilidade da Justiça Restaurativa procurando refletir sobre a importância do (a) PMEC na construção e consolidação da democracia no ambiente escolar e a sua intermediação para a elaboração de mecanismos de intermediação entre família e escola. Com isso, compreender a percepção que possuem - os grupos selecionados: família, PMEC, alunos e profissionais da educação - sobre a necessidade e importância de um profissional, na escola, que promova a intermediação entre escola e comunidade. Finalmente, contribuir para a 
promoção e ampliação da discussão sobre essa temática em razão do ideal de efetivação de uma educação formal com qualidade de ensino e aprendizagem em ambientes escolares democráticos e acolhedores.

Considerando os objetivos elencados, a proposta desse trabalho procurou se pautar pelo desenvolvimento de entrevistas com grupos selecionados de pessoas que estão inseridas diretamente em um ambiente escolar como profissionais da educação e alunos, e outras que contribuíssem e/ou tivessem responsabilidades com os processos que nele se desenvolvem, como a família.

\section{METODOLOGIA}

Esta pesquisa seguiu uma proposta qualitativa quando se propôs à interpretação e reflexão sobre os dados coletados. Efetuou-se também a necessária revisão bibliográfica sobre a temática enfocada que se realizou a partir de registros disponíveis de pesquisas anteriores, nos livros, artigos, teses e documentos impressos. Foram usados dados teóricos já trabalhados por outros pesquisadores e esses textos se tornam fontes dos questionamentos a serem pesquisados (SEVERINO, 2007). Seguindo proposta de Duarte, Mamede e Andrade (2009), o método qualitativo seguirá, sempre que possíveis, mecanismos e/ou procedimentos disponíveis na técnica do Discurso do Sujeito Coletivo, tais como as entrevistas individuais feitas por meio de questionário.

A metodologia científica de Estudo de Caso também está presente, pois conforme André (1995), objetiva estudar determinados grupos sociais que demandam estruturas públicas - escola - (grupo 1 e 2 - alunos e família) e trabalham (grupo 3 - profissionais da educação dentre eles o PMEC) em uma entidade específica, no caso, a Escola Estadual do interior do Estado de São Paulo. Foram entrevistados ao todo 70 pessoas divididos nos três grupos.

O projeto de pesquisa foi apresentado ao CEP da Universidade do Oeste Paulista (UNOESTE), conforme Protocolo 3550, Tipo do Projeto: PEIC, com data de submissão em 11/10/2016. O primeiro parecer do Comitê de Ética em Pesquisa (CEP) foi em 28/11/2016 com sugestões de alterações e correções em alguns pontos do projeto. $O$ segundo parecer foi efetivado em 12/12/2016 com aprovação.

O projeto foi apresentado diretamente aos gestores da escola alvo da pesquisa, tendo o mesmo sido aceito conforme documentação anexada junto ao CEP e Plataforma Brasil, assim como o respectivo Termo de Livre Consentimento.

\section{RESULTADOS}

Em termos da análise dos resultados das entrevistas, ainda não se pode fazer conclusões definitivas, pois os questionários encontram-se em fase de sistematização dos dados. Mas, preliminarmente, percebe-se que nos três grupos houve o destaque da importância do(a) Professor(a) Mediador(a) e Comunitário para a melhoria da relação família-escola, assim como contribui para ampliar as possibilidades relacionais entre aluno-profissionais da educação. Nessa melhoria das relações entre os interessados no processo de ensino e aprendizagem e, consequentemente, da formação para a cidadania, destaca-se a diminuição dos conflitos no ambiente escolar.

Ao se concluir o levantamento dos dados relativos ao questionário aplicado ao grupo de alunos selecionados, foi possível a elaboração da tabela abaixo. Esta tabela apresenta dados referentes às questões aplicadas aos discentes da U.E. pesquisada. Teve trinta alunos participantes os quais responderam a perguntas referentes ao trabalho do/a Mediador/a desenvolvido na instituição escolar.

A primeira pergunta questionada: Você considera que seu comportamento e consequentemente o seu aprendizado melhorou após as conversas com o PMEC? Dos questionados vinte e oito disseram que sim e dois não souberam responder. 
Em relação a segunda pergunta: Você praticou inconscientemente ou sofreu Bullying? Da pergunta realizada, dezesseis alunos responderam que sim, dez que não e quatro não perceberam se sofreram ou não. Ainda nesta questão perguntou-se: Em caso de (sim), as intervenções da PMEC colaboraram para a melhoria e/ou solução dos seus atos ou dos seus possíveis constrangimentos sociais na Unidade Escolar? Dos estudantes que haviam respondido sim, quinze apontaram sim novamente e um disse não saber.

Na terceira questão: Você costuma respeitar as regras e normas desta escola? Esta pergunta contou com quatorze alunos apontando sim, treze não e três não souberem responder. Ainda referente a esta pergunta: Quando ocorre o registro de ocorrências escolares o/a PMEC faz o atendimento e neste orienta e muitas vezes aplica o método de Justiça Restaurativa no qual você e os demais envolvidos sejam alunos, funcionários ou professores entram em acordo sem maiores punições. Como o entrevistado avalia este trabalho desenvolvido pelo/a Professor/a Mediador/a Escolar e Comunitário nesta escola? Dos entrevistados vinte e dois educandos responderam excelente e oito bom.

Sobre a quarta questão: Você considera que houve melhorias em relação à sua aprendizagem após a chegada do (a) PMEC e sua função na escola? Vinte e nove questionados disseram sim e um não soube dizer.

Tabela 1. Questões direcionadas a 30 aluno (a) da instituição escolar, 2017.

\begin{tabular}{|c|c|c|c|c|c|c|c|c|}
\hline Questões & Sim & Não & $\begin{array}{c}\text { Não } \\
\text { sei }\end{array}$ & $\begin{array}{c}\text { Não } \\
\text { percebeu }\end{array}$ & Excelente & Bom & Ruim & Péssimo \\
\hline 1 & 28 & 0 & 2 & & & & & \\
\hline 2 & 16 & 10 & 1 & 4 & & & & \\
\hline 3 & 14 & 13 & 3 & & 22 & 8 & & \\
\hline 4 & 29 & & 1 & & & & & \\
\hline
\end{tabular}

Fontes: próprias coletadas junto a 30 entrevistados pelos pesquisadores

Em termos de percepções da família, Na tabela 2 - abaixo destacado - são apresentados os resultados com as entrevistas efetuadas com 30 pais e/ou responsáveis dos alunos na faixa etária de 11 anos a 17 anos, na qual o/a mediador/a procurou desenvolver o trabalho de pesquisa com pais mais frequentes na escola, ou seja, de alunos indisciplinados ou com risco de vulnerabilidade.

Tabela 2. Questões direcionadas para aos 30 pais e/ou responsável (eis) da instituição escolar, 2017.

\begin{tabular}{|c|c|c|c|}
\hline Questões & Sim & Não & Não sei \\
\hline 1 & 29 & 0 & 1 \\
\hline 2 & 29 & 1 & 0 \\
\hline 3 & 29 & 0 & 1 \\
\hline 4 & 20 & 10 & 0 \\
\hline 5 & 28 & 0 & 2 \\
\hline
\end{tabular}

Fontes: próprias coletadas junto a 30 entrevistados pelos pesquisadores

Em relação às percepções dos profissionais educadores da unidade escolar, foram entrevistados um total de sete professores, três a menos do foi sugerido no projeto original da pesquisa. Considerando a primeira questão: Você considera que houve melhorias em relação ao ensino aprendizagem após a chegada do (a) PMEC e sua função na escola? A totalidade dos educadores responderam que sim. 
Tabela 3. Questões direcionadas aos 7 professores (as) da instituição escolar, 2017.

\begin{tabular}{|c|c|c|c|}
\hline Questões & Sim & Não & Não sei \\
\hline 1 & 7 & 0 & 0 \\
\hline 2 & 7 & 0 & 0 \\
\hline 3 & 6 & 0 & 1 \\
\hline 4 & 6 & 1 & 0 \\
\hline
\end{tabular}

Fontes: próprias coletadas junto a 30 entrevistados pelos pesquisadores

\section{DISCUSSÃO}

Por meio de revisão de literatura e sabendo da importância do trabalho do(a) PMEC definese, preliminarmente, que mediação é um procedimento utilizado para resolver conflitos interpessoais e entre seus pares e para os quais a intervenção só ocorre no final do diálogo, portanto, após todos manifestarem seus problemas e levantarem hipóteses para solucionar tais ocorrências. Cabe neste momento que uma terceira pessoa promova a possibilidade de conciliação entre os envolvidos aplicando, quando possível, o método da Justiça Restaurativa. Para fundamentar tal conceito (TORRADA, 2015).

Em sendo assim "[...] sua aplicabilidade não se restringe à Ciência do Direito, mas se estende a uma infinidade de outras áreas. O termo mediação procede do latim mediare, que significa mediar, intervir, dividir ao meio" (ROBERTS; PASTOR apud MORAIS; SPENGLER, 2009, p. 147).

Em linhas gerais o/a (PMEC) trabalha por meio da equanimidade diante dos conflitos oportunizando desta forma às partes, mecanismos para criarem autonomia crítica e responsabilidade em relação as ocorrências que os mesmos sejam capazes de admitir e seus erros, procurando solucioná-los de forma coerente com a situação adversa.

Ainda procurando definir a característica do Mediador e já tendo conhecimento que este deve ter um terceiro olhar, aquele que não pune e sim que facilita o pensar e solucionar os conflitos utilizando a Justiça Restaurativa e de acordo com Cintra, Dinamarco e Grinover (2006, p. 34):

[...] em ambos procedimentos os interessados utilizam a intermediação de um terceiro, particular, para chegarem à pacificação de seu conflito. Entretanto, ao passo que a conciliação busca, sobretudo o acordo entre as partes, a mediação objetiva trabalhar o conflito, surgindo o acordo como uma mera consequência.

Partindo desses conceitos de que o/a Professor (a) Mediador (a) Escolar e Comunitário (PMEC) deve ter imparcialidade nas soluções de conflitos no ambiente escolar e que é fundamental seu trabalho para garantir os Direitos Humanos a aqueles que estão em casos de vulnerabilidade social, segue a Resolução SE 7, de 19-1-2012. Essa resolução em seus artigos, procura definir como seria o bom desenvolvimento da função do/a PMEC, na Unidade Escolar, sendo que, em seu artigo 70 descreve as funções do mediador escolar, atuando o mesmo para:

I - adotar práticas de mediação de conflitos no ambiente escolar e apoiar o desenvolvimento de ações e programas de Justiça Restaurativa; II - orientar os pais dos alunos, ou responsáveis, sobre o papel da família no processo educativo; III - analisar os fatores de vulnerabilidade e de risco a que possam estar expostos os alunos; IV - orientar a família, ou responsáveis, quanto à procura de serviços de proteção social; $V$ - identificar e sugerir atividades pedagógicas complementares, a serem realizadas pelos alunos fora do período letivo; $\mathrm{VI}$ - orientar e apoiar os alunos na prática de seus estudos. (SÃO PAULO, 2012, S/P) 
É de extrema importância que o profissional na resolução dos conflitos na escola tenha parceria com a equipe gestora e em conjunto articulem e promovam ações para minimizar situações conflituosas, pois, a instituição e seu corpo docente não devem estar aptos apenas a promoverem condições para o ensino e a aprendizagem e, assim, possibilitarem a transmissão e produção de conhecimentos, mas, sim envolverem-se nas relações que construam um novo educar que possibilite bom convívio social entre os frequentadores e futuros cidadãos. Para Gonçalves (2015, p.10):

A escola é uma das instituições responsáveis pela formação dos indivíduos, e sua existência fundamenta-se, sobretudo, na necessidade de transferir às gerações mais novas conhecimentos, atitudes, crenças e valores, abrindoIhes possibilidades para novas realizações.

Sendo assim, a instituição escolar e equipe ficam encarregadas não apenas do educar, mas, principalmente de trabalhar os padrões de convivência, o respeito, a educação de "berço", valores que ao longo das décadas foram se perdendo devido às genitoras saírem para o trabalho e assim deixarem a educação a critério e função dos docentes.

\section{CONCLUSÕES}

Embora a pesquisa não tenha ainda terminado, pois não se efetivou a totalidade da sistematização e análises dos dados coletados na pesquisa de campo, percebe-se que pais e alunos têm a percepção da importância do trabalho desenvolvido na unidade escolar selecionada pelo(a) Professor(a) Mediador(a) Escolar e Comunitário.

Pelo levantamento bibliográfico efetuado e análises das legislações pertinentes à função de Professor(a) Mediador(a) Escolar e Comunitário, também essa importância é destacada, tanto na minimização dos conflitos intramuros escolares, como também em outros ambientes.

As escolas devem construir e podem executar mecanismos simples, que levam ao bom desempenho da relação de ensino e aprendizagem, como também atrair a família dos educandos e eles próprios, para o processo de ensino e de aprendizagem, para tanto, é fundamental a percepção da mediação escolar no estabelecimento da proximidade entre os envolvidos e na busca de soluções aos conflitos que podem ocorrer entre eles. Ao se minimizar os conflitos, contribui-se para a melhoria das relações processuais ao ensino e a aprendizagem e, consequentemente, para a melhoria da educação e formação dos educandos.

\section{REFERÊNCIAS}

ANDRÉ, Marli E. D. Afonso de. Etnografia da prática escolar. Campinas-SP: Papirus, 1995.

CINTRA, Antônio Carlos de Araújo; DINAMARCO, Cândido Rangel; GRINOVER, Ada Pelegrini. Teoria Geral do Processo. 22. Ed. São Paulo: Malheiros, 2006.

DUARTE, S. J. H.; MAMEDE, M. V. e ANDRADE, S. M. O. Opções Teórico-Metodológicas em Pesquisas Qualitativas: Representações Sociais e Discurso do Sujeito Coletivo. Saúde Soc. São Paulo, v.18, n.4, p.620-626, 2009. In: http://www.scielo.br/pdf/sausoc/v18n4/06.pdf - Acesso em $\underline{20 / 08 / 2015}$

GONÇALVES, Maria Augusta Salin. Construção da Identidade moral e práticas educativas (livro eletrônico) Maria Augusta Salin Gonçalves- Campinas, SP Papirus, 2015.

SÃO PAULO, Secretaria da Educação. Resolução SE 7. São Paulo ; Secretaria da Educação do Estado de São Paulo, 2012. 
SEVERINO, Antônio Joaquim. Metodologia do Trabalho Científico. 23 ed. rev. E atual.-São Paulo: Cortez, 2007.

TORRADA, D. Mediação: um novo olhar para o tratamento de conflitos no Brasil. Disponível em: http://www.ambitojuridico.com.br/site/?n link=revista artigos leitura\&artigo id=10864\&revista caderno=21. Acesso em: 26 set. 2015. 